RESEARCH PAPER

\title{
Mechanochemical Synthesis and Potentiation of the Antimicrobial Activity of 4-[3-(4-methoxyphenyl)-allylideneamino]-1,5-dimethyl-2-phenylpyrazol-3-one by Metal Chelation
}

\author{
Aguzue Onyinye Chinelo*1, Oviawe Amowie Phillip ${ }^{2}$, Adebiyi Adedayo ${ }^{1}$ \\ ${ }^{1}$ Sheda Science and Technology Complex, Abuja, Nigeria \\ ${ }^{2}$ Department of Chemistry, University of Benin, Nigeria \\ *Corresponding author: aguzueonyii@gmail.com
}

DOI: https://doi.org/10.37134/jsml.vol8.2.3.2020

Received: 29 January 2020; Accepted: 5 March 2020; Published: 9 March 2020

\begin{abstract}
A Schiff base ligand, 4-[3-(4-methoxyphenyl)-allylideneamino]-1,5-dimethyl-2-phenylpyrazol-3-one has been synthesized by the condensation of Methoxycinnamaldehyde and 4-aminoantipyrine. Its divalent metal complexes of $\mathrm{Co}, \mathrm{Ni}$, and $\mathrm{Cu}$ were also synthesized using the mechanochemical solvent-free method. The ligand and the complexes were characterized by FTIR, UV/visible, ${ }^{1} \mathrm{H}$ NMR, ${ }^{13} \mathrm{C}$ NMR, and GC-MS. The ligand behaved as a bidentate donor by using its carbonyl and azomethine $\mathrm{N}$ as binding sites for the metals. The ligand showed low activity against some microbes but the complexes were remarkably active against the fungi species.
\end{abstract}

Keywords: mechanochemical; methoxycinnamaldehyde; 4-[3-(4-methoxyphenyl)-allylideneamino]-1,5dimethyl-2-phenylpyrazol-3-one; 4-aminioantipyrine

\section{INTRODUCTION}

Schiff base is derived by the condensation reaction of aldehydes or ketones and primary amines (Bahl and Bahl, 1993). There are several works on Schiff bases and more researches is ongoing because they have served as synthetic intermediates and have wide applications in natural products, pharmacology, industries, mineralogy and other interdisciplinary sciences (Abdul, 2005). In light of these significances, a variety of synthetic strategies have been developed for the preparation of Schiff base. The solvent-free reactions are green methods in a synthesis that have numerous advantages: reduced pollution, low cost, and simplicity in process and handling (Tanaka and Toda, 2005). In this work, we have synthesized a Schiff base ligand by mechanochemical solvent-free reaction between methoxycinnamaldehyde and 4-aminoantipyrine (4-amino-2,3dimethyl-1-phenylpyrazal-5-one). Methoxycinnamaldehyde is an active constituent of Agastche rugosa, a medicinal plant of traditional Chinese medicine and has been reported to have extensive antimicrobial activities and antiviral activity (Kuo et al., 2009; Ooi et al., 2006). Antipyrine is very much used in medicine and it's believed that its amino derivative would equally be of much use in medicine possibly as intermediates in antipyretic and analgesic drugs (Agarwal et al., 2006). 


\section{MATERIAL AND METHODS}

\section{Chemicals and reagents}

All reagents used in this analysis are of analytical grade and obtained from Sigma-Aldrich Chemical Ltd and BDH chemicals. The reagents include Methoxycinnamaldehyde, 4aminoantipyrine, dimethyl sulphoxide (DMSO), dimethylformamide (DMF), $\mathrm{NiSO}_{4} \cdot 6 \mathrm{H}_{2} \mathrm{O}$, $\mathrm{CuCl}_{2} .2 \mathrm{H}_{2} \mathrm{O}$, and $\mathrm{CoCl}_{2} \cdot 6 \mathrm{H}_{2} \mathrm{O}$.

\section{Instrumental analysis}

The melting point was detected using the melting point apparatus, electronic spectra were determined using Cecil UV C.E7500 7000 series spectrophotometer. IR spectra were also determined using the FTIR-8400S spectrophotometer. ${ }^{1} \mathrm{H}-\mathrm{NMR}$ and ${ }^{13} \mathrm{C}-\mathrm{NMR}$ were recorded in $\mathrm{D}_{6}$-DMSO on a Bruker FT-NMR spectrometer. The GC-MS was performed using QP2010 plus Shimadzu. The melting point of the ligands and complexes were recorded using a Gallenkamp Melting Point Apparatus with a thermometer range of 0-360 ${ }^{\circ} \mathrm{C}$.

\section{Molar conductance}

The molar conductances of each of the metal (II) complexes were determined using 430 Jenway conductivity meter at a concentration of $10^{-3} \mathrm{M}$ in DMSO. This measurement is used to determine whether a given compound is an electrolyte or a non-electrolyte in solution. Molar conductance is the conductivity of an electrolyte solution divided by the molar concentration of the electrolyte and so, measures the efficiency with which a given electrolyte conducts electricity in solution.

\section{Synthesis of 4-[3-(4-methoxyphenyl)-allylideneamino]-1,5-dimethyl-2-phenylpyrazol-3-one}

The Schiff base derived from methoxycinnamaldehyde and 4-aminioantipyrine was prepared by carefully weighing $2.03 \mathrm{~g}(0.01 \mathrm{~mol})$ of 4-aminoantipyrine and $1.62 \mathrm{~g}(0.01 \mathrm{~mol})$ methoxy cinnamaldehyde into a clean ceramic mortar and ground at room temperature for 20 mins. The resultant was stored in a desiccator over the $\mathrm{CaCl}_{2}$ vacuum ${ }^{8}$. The yield was recorded.

\section{Synthesis of the complexes}

The complexes were prepared by the reaction of the ligand $(0.01 \mathrm{~mol})$ with the respective metal (II) salts under mechanochemical solvent-free condition, $0.01 \mathrm{~mol} \mathrm{NiSO}_{4} .6 \mathrm{H}_{2} \mathrm{O}(2.63 \mathrm{~g}) ; 0.01 \mathrm{~mol}$ $\mathrm{CuCl}_{2} .2 \mathrm{H}_{2} \mathrm{O}(1.72 \mathrm{~g})$ and $0.01 \mathrm{~mol} \mathrm{CoCl}_{2} .6 \mathrm{H}_{2} \mathrm{O}(2.38 \mathrm{~g})$. The various $0.01 \mathrm{~mol}$ of the metal salts were each ground with $0.01 \mathrm{~mol}$ of the ligand in mortar for 20 mins. The resultant was collected without further purification and stored in the desiccator (Suresh et al., 2012). The yield was recorded.

\section{Antimicrobial sensitivity test}

The sensitivity tests on the samples were carried out using the agar well diffusion method (Sulekh et al., 2009). The nutrient agar was prepared according to the manufacturer's recommendation and was poured into Petri dishes to set. The test organisms; bacteria positive gram: Pseudomonas aereginosa and Escherichia coli and negative gram: Staphylococcus aureus and Bacillus subtillis; Fungi: Candida albicans were cultured. The overnight broth cultures of the test organisms were properly diluted to the turbidity of Macfarland's standards and were inoculated on the surface of the agar. The inoculated agar was left for 20 minutes and holes were bored into it using corn borer. The prepared ligand and complexes were dissolved in DMSO and were then introduced into the 
agar using a sterile swab stick. The inoculated plates were then incubated at $37^{\circ} \mathrm{C}$ for 18 hours thereafter the resultant zones of inhibition were measured using meter rule and results obtained in centimeters were recorded. Ciprofloxacin and fluconazole which are antibacterial and antifungal agents respectively were used as control drugs.

\section{RESULTS AND DISCUSSION}

\section{Synthesis of 4-[3-(4-methoxyphenyl)-allylideneamino]-1,5-dimethyl-2-phenylpyrazol-3-one ligand}

The synthesis of 4-[3-(4-methoxyphenyl)-allylideneamino]-1,5-dimethyl-2-phenylpyrazol-3-one ligand is shown in Figure 1. All the complexes were air-stable, colored solids and nonhygroscopic. The physical properties of the compounds are presented in Table 1.

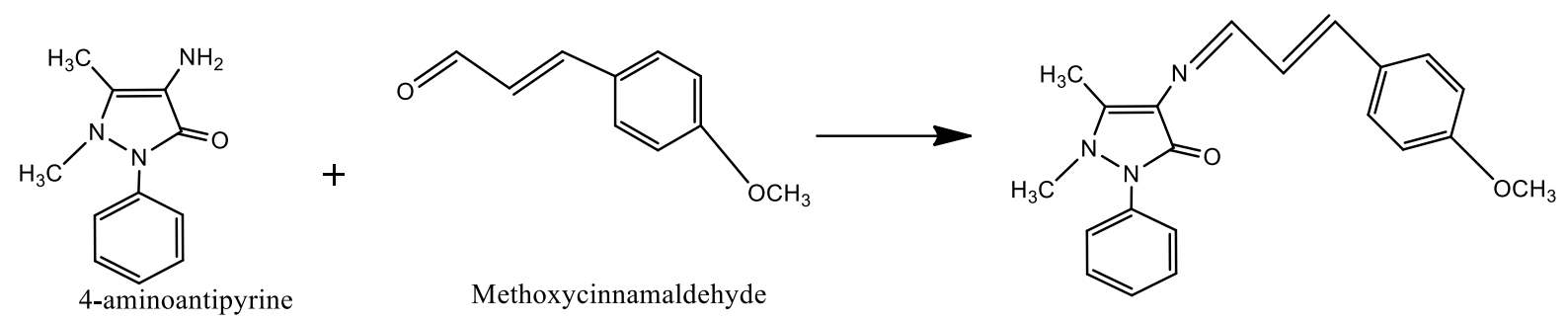

Figure 1. Synthesis of 4-[3-(4-methoxyphenyl)-allylideneamino]-1,5-dimethyl-2-phenylpyrazol-3-one ligand.

Table 1. Physical properties of the ligand and complexes.

\begin{tabular}{llllll}
\hline Compounds & Colour & MW & MP & Yield (\%) & Molar conductance \\
\hline $\mathrm{L}^{*}$ & Yellow & 347 & $166-168^{\circ} \mathrm{C}$ & 82.2 & \\
$\mathrm{CoL}$ & Greenish yellow & 576 & $185-186^{\circ} \mathrm{C}$ & 62.6 & 23.7 \\
$\mathrm{NiL}$ & Lemon green & 608 & $166-168^{\circ} \mathrm{C}$ & 62.2 & 3.86 \\
$\mathrm{CuL}$ & Brown & 509 & $178-180^{\circ} \mathrm{C}$ & 60.0 & 39.1 \\
\hline
\end{tabular}

*L: 4-[3-(4-methoxyphenyl)-allylideneamino]-1,5-dimethyl-2-phenylpyrazol-3-one; MW: molecular weight; MP: melting point

\section{Infra-red spectra}

The infra-red spectra of the ligand and complexes are presented in Table 2. The infra-red spectra of cobalt and nickel complex exhibited a broadband at 3393 and $3414 \mathrm{~cm}^{-1}$ respectively. These are due to the presence of water molecules. The sharp bands between $1563-1598 \mathrm{~cm}^{-1}$ are due to $\mathrm{C}=\mathrm{N}$ azomethine vibrations. The free ligand has the $\mathrm{C}=\mathrm{N}$ vibration at $1592 \mathrm{~cm}^{-1}$ so the shifting of the band to higher or lower frequencies in the complexes indicates complexation (Quiroga et al., 1988). The bands that appeared below $650 \mathrm{~cm}^{-1}$ are assigned to the metal-nitrogen (M-N), metaloxygen (M-O) and metal chlorine (M-Cl) bonds. 
Table 2. Infrared data of the ligand and complexes $\left(\mathrm{cm}^{-1}\right)$.

\begin{tabular}{llllllll}
\hline Compounds & $\mathbf{O H}, \mathbf{H}_{2} \mathbf{O}$ & $\mathbf{C}-\mathbf{H}$ Aromatic & $\mathbf{C}=\mathbf{O}$ & $\mathbf{C = N}$ & $\mathbf{C = C}$ Aromatic & M-N & M-Cl \\
\hline $\mathrm{L}^{*}$ & - & 3029 & 1624 & 1592 & 1462 & - & - \\
$\mathrm{CoL}$ & 3393 & 2924 & 1639 & 1575 & 1458 & 503 & 398 \\
$\mathrm{NiL}$ & 3414 & 2985 & 1650 & 1598 & 1421 & 567 & 456 \\
$\mathrm{CuL}$ & - & 3029 & 1640 & 1563 & 1490 & 589 & 424 \\
\hline
\end{tabular}

*L: 4-[3-(4-methoxyphenyl)-allylideneamino]-1,5-dimethyl-2-phenylpyrazol-3-one

\section{UV/Visible electronic spectra}

The electronic spectra of the ligand and its complexes were recorded and shown in Table 3. The ligand's spectra data displayed three bands at $422 \mathrm{~nm}, 347 \mathrm{~nm}$, and $317 \mathrm{~nm}$ which resulted from Intra ligand charge transfer due to the $\pi \rightarrow \pi^{*}$ transition of the phenyl bonds and $n \rightarrow \pi^{*}$ transition of the $\mathrm{C}=\mathrm{N}$ bonds (El-Hassy, 2004). Co (II) complex showed two absorption frequencies at 674 $\mathrm{nm}$ and $420 \mathrm{~nm}$. The transitions have been assigned to metal to ligand charge transfer (MLCT) or ligand to metal charge transfer (LMCT) and $d \rightarrow d$ transitions. In the case of $\mathrm{Ni}(\mathrm{II})$ complex $\left(\mathrm{L}_{2} \mathrm{Ni}\right)$, three absorption bands were observed at $420 \mathrm{~nm}, 343 \mathrm{~nm}$, and $330 \mathrm{~nm}$. Cu (II) complex exhibited bands at $428 \mathrm{~nm}$ and $348 \mathrm{~nm}$. The intense absorption was due to MLCT or LMCT and the weak absorption has been assigned to $\mathrm{d} \rightarrow \mathrm{d}$ transition.

Table 3. UV/Visible electronic spectra data and possible assignments

\begin{tabular}{llll}
\hline Compounds & $\boldsymbol{\lambda} \mathbf{n m}$ & $\boldsymbol{\lambda} \mathbf{n m}$ & $\boldsymbol{\lambda} \mathbf{n m}$ \\
\hline $\mathrm{L}^{*}$ & 422 & 347 & 317 \\
$\mathrm{CoL}$ & 674 & 42 & - \\
$\mathrm{NiL}$ & 420 & 343 & 330 \\
$\mathrm{CuL}$ & 428 & 348 & - \\
\hline
\end{tabular}

*L: 4-[3-(4-methoxyphenyl)-allylideneamino]-1,5-dimethyl-2-phenylpyrazol-3-one

\section{${ }^{1} \mathrm{H}-\mathrm{NMR}$ spectral data}

The ${ }^{1} \mathrm{H}-\mathrm{NMR}$ signal at $2.41 \mathrm{ppm}(3 \mathrm{H}, \mathrm{s})$ is assigned to the antipyrine methyl proton, $\mathrm{H}_{3} \mathrm{C}-\mathrm{C}$. The signal at $3.89 \mathrm{ppm}(3 \mathrm{H}, \mathrm{s})$ is assigned to methyl proton, $\mathrm{H}_{3} \mathrm{C}-\mathrm{O}$, while the signal at $3.10 \mathrm{ppm}(3 \mathrm{H}$, $\mathrm{s})$ is assigned to the methyl proton, $\mathrm{H}_{3} \mathrm{C}-\mathrm{N}$. The signals at $7.02 \mathrm{ppm}(1 \mathrm{H}, \mathrm{d})$ and $6.85 \mathrm{~m}(1 \mathrm{H}, \mathrm{d})$ are assigned to ethylene protons, $\mathrm{HC}=\mathrm{C}(\mathrm{H}) \mathrm{C}$. The signal at $9.52 \mathrm{ppm}$ is assigned to azomethine proton, $\mathrm{C}(\mathrm{H})=\mathrm{N}$. The azomethine proton $(\mathrm{HC}=\mathrm{N})$ appeared at $9.52 \mathrm{ppm}$ for the ligand but shifted upfield $(9.39 \mathrm{ppm})$ for the complex showing complexation through the azomethine linkage (El-Hassy, 2004).

\section{${ }^{13}$ C-NMR spectral data}

The ${ }^{13} \mathrm{C}$-NMR spectrum of the ligand gave a satisfactory result. The peak at $160.21 \mathrm{~m}$ is assigned to the azomethine $\mathrm{C}=\mathrm{N}$ carbon. The peaks at $10.18 \mathrm{ppm}, 35.89 \mathrm{ppm}, 55.35 \mathrm{ppm}$ are assigned to the methyl carbons. The peaks at $114.24 \mathrm{ppm}$ and $124.38 \mathrm{pp} \mathrm{m}$ are assigned to the $\mathrm{HC}=\mathrm{CH}$. The peaks at $128.79 \mathrm{ppm}$ and $129.17 \mathrm{ppm}$ are assigned to the benzene carbon attached to the antipyrine. The peak at $16.21 \mathrm{ppm}$ is assigned to the benzene carbon attached to $\mathrm{O}-\mathrm{CH}_{3}$. (Obasi L. N. et al., 216; Shipman et al., 1986). 


\section{GC-MS spectral data}

In the GC-MS analysis of ligand, there were many peaks. The molecular ion peak of the ligand had a mass/charge $(\mathrm{m} / \mathrm{z})$ ratio of 347 which corresponded to the molecular mass of the compound. The base peak had $m / z$ ratio at 318 . Other fragments occurred at 33, 45, 55, 77, 89, 104, 117, 133, 161, 187, 234, 29 and 318. The major fragmentations are represented in Scheme 1.

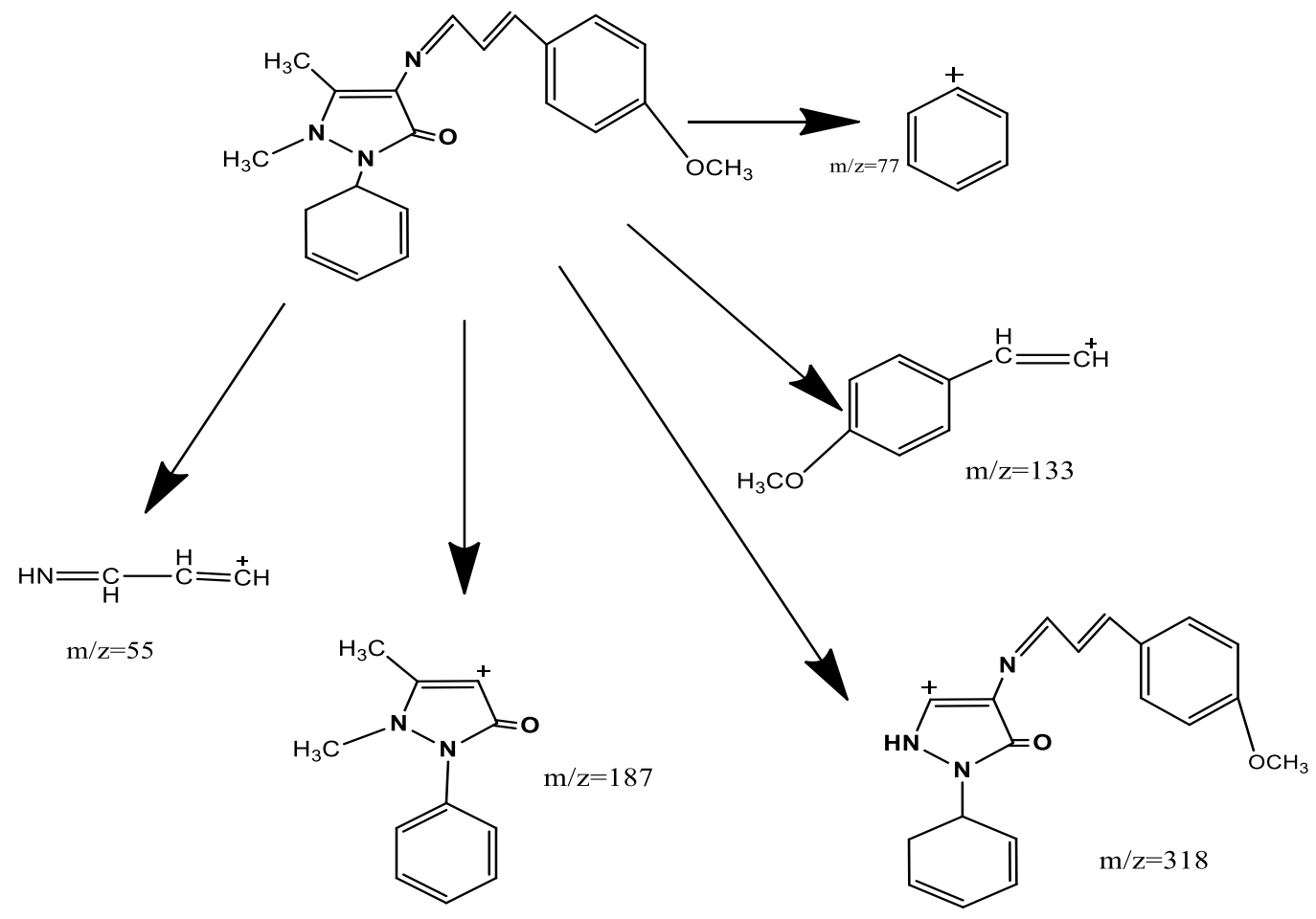

Scheme 1. Mass fragmentation of ligand.

\section{Antimicrobial activity}

The results in Table 4 are zones of inhibition. From the results, we can see that the complexes proved potent against some bacteria and especially the fungus more than the ligand. Complexation improved the antimicrobial activities of the ligand. CoL inhibited the growth of all the organisms used in this work more than other complexes except for Bacillus subtillis which NiL inhibited most. But NiL, showed no activity against Escherichia coli and Staphylococcus aureus. CuL was only active against Staphylococcus aureus and Candida albicans, with the lowest activity when compared to the other complex (Aguzue, 2019). The control drugs were ciprofloxacin and fluconazole for the bacteria and fungi respectively. 
Table 4. Antimicrobial test results

\begin{tabular}{lccccc}
\hline Compounds & $\begin{array}{c}\text { Escherichia } \\
\text { coli }\end{array}$ & $\begin{array}{c}\text { Pseudomonas } \\
\text { aeureginosa }\end{array}$ & $\begin{array}{c}\text { Bacillus } \\
\text { subtillis }\end{array}$ & $\begin{array}{c}\text { Staphylococcous } \\
\text { aureus }\end{array}$ & $\begin{array}{c}\text { Candida } \\
\text { albicans }\end{array}$ \\
\hline $\mathrm{L}^{*}$ & - & - & $10 \mathrm{~cm}$ & $15 \mathrm{~cm}$ & $9 \mathrm{~cm}$ \\
$\mathrm{CoL}$ & $15 \mathrm{~cm}$ & $21 \mathrm{~cm}$ & $22 \mathrm{~cm}$ & $20 \mathrm{~cm}$ & $15 \mathrm{~cm}$ \\
$\mathrm{NiL}$ & - & $16 \mathrm{~cm}$ & $23 \mathrm{~cm}$ & - & $12 \mathrm{~cm}$ \\
$\mathrm{CuL}$ & - & - & - & $17 \mathrm{~cm}$ & $13 \mathrm{~cm}$ \\
Control & $14 \mathrm{~cm}$ & $10 \mathrm{~cm}$ & $15 \mathrm{~cm}$ & - & $13 \mathrm{~cm}$ \\
\hline
\end{tabular}

*L: 4-[3-(4-methoxyphenyl)-allylideneamino]-1,5-dimethyl-2-phenylpyrazol-3-one

\section{CONCLUSION}

The mechanochemical synthesis and potentiation of the antimicrobial activity of 4-[3-(4methoxyphenyl)-allylidenea mino]-1,5-dimethyl-2-phenylpyrazol-3-one by metal chelation have been studied. The Schiff base ligand, 4-[3-(4-methoxyphenyl)-allylideneamino]-1,5-dimethyl-2phenylpyrazol-3-one have been synthesized by the condensation of methoxycinnamaldehyde and 4-aminoantipyrine. Its divalent metal complexes of $\mathrm{Co}, \mathrm{Ni}$, and $\mathrm{Cu}$ were also synthesized. The ligand and the complexes have been characterized by FTIR, UV/visible, ${ }^{1} \mathrm{HNMR},{ }^{13} \mathrm{C}-\mathrm{NMR}$, and GCMS. The ligand behaved as a bidentate donor by using its carbonyl and azomethine $\mathrm{N}$ as binding sites for the metals. The ligand showed low activity against some microbes but the complexes were remarkably active against some of the bacteria and especially the fungi species. We hereby suggest that this ligand and its metal complexes (especially the Cobalt) be considered as metal-based drugs.

\section{REFERENCES}

Abdul, R. (2005). Synthesis and biological studies of some Schiff base compounds and their transition metal complexes. (Ph.D Thesis). Babauddin Zakariya University, Pakistan.

Agarwal, R.K., Singh, L., Sharma, D.K. (2006). Synthesis, spectral, and biological properties of copper(II) complexes of thiosemicarbazones of Schiff bases derived from 4-aminoantipyrine and aromatic aldehydes. Bioinorganic Chemistry and Applications, 1, 1-10.

Aguzue, O.C. (2019). Spectroscopic characterization and biological properties of schiff base ligands derived from cinnamaldehyde and their metal complexes of $\mathrm{Co}$, $\mathrm{Ni}$ and $\mathrm{Cu}$. Ph.D Thesis University of Benin.

Bahl, B.S., Bahl, A. (1993). Elementary Organic Chemistry, Schand and Company Ltd, New Delhi.

El-Hassy, N.A. (2004). Synthesis and investigation of tridentate Schiff base chelates. Master Thesis Benghazi Garyounis University.

Kuo, C.H., Jung, S.C., Lien, C.C., Chun, C.L. (2009). 4-methoxycinnamaldehyde inhibited human respiratory syncytial virus in a human larynx carcinoma cell line. Phytomedicine, 16, 882-886.

Obasi, L. N., Kaior, G. U., Rhyman, L., Alswaidan, I. A., Fun, H. K., (2016). Synthesis, characterization, antimicrobial screening and computational studies of 4-[3-(4-methoxy-phenyl)-allylideneamino]1,5-dimethyl-2-phenyl-1,2-dihydro-pyrazol-3-one. Journal of Molecular Structure, 1120, 180-186.

Ooi, L.S., Li, Y., Kam, S.L., Wang, E.Y., Ooi, V.E. (2006). Antimicrobial activities of cinnamon oil and cinnamaldehyde from the Chinese medical herb Cinnamonium cassia Blume. The American Journal of Chinese Medicine, 34, 511-522. 
Quiroga, A.G., Perez, J.M., Lopez-Solera, I. (1988). Novel tetranuclear orthometalated complexes of Pd(II) and $\mathrm{Pt}(\mathrm{II})$ derived from pisopropylbenzaldehyde thiosemicarbazone with cytotoxic activity in cisDDP resistant tumor cell lines Interaction of these complexes with DNA. Journal of Medicinal Chemistry, 41(9), 1399-1408.

Scovill, J.P., Klayman D.L., Franchino, C.F. (2009). 2-acetylpyridine thiosemicarbazones complexes with transition metals as antimalarial and antileukemic agents. Journal of Medicinal Chemistry, 25(10), 1261-1264.

Shipman, J. (1986). Thiosemicarbazones of 2-acetylpyridine, 2-acetylquinoline, 1-acetylisoquinoline, and related compounds as inhibitors of herpes simplex virus in vitro and in a cutaneous herpes guinea pig model. Antiviral Research, 6(4), 197-222.

Sulekh, C., Amit, K.S. (2009). Antitingal and spectra studies of Cr(III) and Mn(II) compexes derived from 3, 31-thiodropropionic acid derivative. International Journal of Inorganic Chemistry, 89, 1-4.

Suresh, P., Jdhav, S.D., Shinde, S.K. (2012). CES as an efficient natural catalyst for synthesis of Schiff bases under solvent-free conditions: an innovative green approach. Organic Chemistry International, $10,1-5$.

Tanaka, K., Toda, F. (2000). Solvent free organic synthesis. Chemistry Reviews, 100, 1024-1074. 